\title{
Serological Studies with Bovine Ureaplasmas (T-Mycoplasmas)
}

\author{
C. J. HOWARD, R. N. GOURLAY, AND JACQUELINE COLLINS \\ Agricultural Research Council, Institute for Research on Animal Diseases, Compton, Newbury, \\ Berkshire, England
}

\begin{abstract}
Seventy-seven recently isolated bovine ureaplasma (T-mycoplasma) strains were compared by the growth inhibition test with previously reported strains. The complex serological nature of the group was confirmed. Only five of the fresh isolates did not react with antisera to the eight representative bovine strains proposed previously. The suggestion that the serological diversity of the group might be represented by a small number of strains has thus been confirmed. Eleven strains are proposed as representatives of this serological diversity. No common antigens were shown between Ureaplasma urealyticum, the ureaplasmas of human origin, and the bovine isolates.
\end{abstract}

Ureaplasmas, mycoplasmas with urease activity previously called T-mycoplasmas (12), have been isolated from a variety of diseased and apparently nondiseased bovine tissues. The anatomical sites in cattle from which these mycoplasmas have been isolated include eyes, the urogenital tract, and respiratory tract (13). To determine whether some relationship exists between disease and the presence of ureaplasmas, it would be useful to have a means of serologically identifying strains. Reported studies $(5,6$, 9 ) indicate that bovine ureaplasmas are serologically heterogeneous. However, it has been suggested that the serological diversity of the group could be represented by a small number of strains which possess between them the spectrum of antigens synthesized by the group (6). To test this suggestion and to study further the serology of the bovine ureaplasmas, a number of fresh isolates were collected and examined to determine how many of them showed serological cross-reactions with the eight bovine strains previously put forward as representing the group.

\section{MATERIALS AND METHODS}

Media. The broth used to culture ureaplasmas, designated U4, consisted of Hanks balanced salt solution (Wellcome, Beckenham, England) (10X concentrate), $4 \mathrm{ml}$; Hartley digest broth, $20 \mathrm{ml}$; fetal calf serum (Flow Laboratories, Irvine, Calif.), $15 \mathrm{ml}$; yeast extract (Distillers Co., Morden, England) (25\% [wt/vol] aqueous extract), $10 \mathrm{ml} ; 1 \%$ phenol red, 0.2 ml; $20 \%$ urea, $0.25 \mathrm{ml} ; 5 \%$ thallium acetate, $0.5 \mathrm{ml}$; magnesium sulfate $(250 \mu \mathrm{g} / \mathrm{ml}), 1 \mathrm{ml}$; benzylpenicillin (Glaxo Ltd., Greenford, England) $(200,000 \mathrm{U} / \mathrm{ml}), 0.5$ $\mathrm{ml}$. Glass-distilled double-deionized water was added to bring the volume to $100 \mathrm{ml}$, and the $\mathrm{pH}$ was adjusted to 6.0 to 6.2 by the addition of $N$-hydrochloric acid.

The solid medium consisted of: Hanks buffered salt solution ( $10 \times$ concentrate), $4 \mathrm{ml}$; agarose (Miles Labs,
Slough, England), $0.8 \mathrm{~g} ; \mathrm{N}$-2-hydroxyethyl piperazine$\mathrm{N}^{\prime}$-2-ethanesulfonic acid (Sigma Chemical Co., St. Louis, Mo.), $1.19 \mathrm{~g}$; Hartley broth, $20 \mathrm{ml}$; glass-distilled water, $44 \mathrm{ml}$. This mixture was sterilized by autoclaving at $10 \mathrm{lb} / \mathrm{in}^{2}$ for $10 \mathrm{~min}$. After cooling to $56^{\circ} \mathrm{C}$ the following were added: fetal calf serum, $20 \mathrm{ml} ; 1 \%$ putrescine, $1 \mathrm{ml} ; 0.9 \%$ L-cysteine, $1 \mathrm{ml}$; and yeast extract, penicillin, thallium acetate, and magnesium sulfate at the concentrations noted above. The final $\mathrm{pH}$ of the solid medium was about 6.2. Cultures on solid media were incubated at $33^{\circ} \mathrm{C}$ under an atmosphere of $100 \% \mathrm{CO}_{2}$ except for a few strains, the growth of which was inhibited by $100 \% \mathrm{CO}_{2}$, and these were grown under $\mathrm{N}_{2}$ containing $5 \% \mathrm{CO}_{2}$.

Antisera. Antisera were raised in New Zealand white rabbits. The growth from 1-liter broth cultures was harvested by centrifugation, washed three times with $0.15 \mathrm{M}$ phosphate-buffered saline (pH 7.2), and resuspended in a final volume of $2.5 \mathrm{ml}$. Rabbits were inoculated intramuscularly at two sites with $1 \mathrm{ml}$ of organisms mixed with an equal volume of $4 \%$ sodium alginate. Three intravenous injections were given at 2day intervals beginning 14 days after the intramuscular inoculation, and the animals were exsanguinated 7 days after the final intravenous inoculation.

Serological tests. The growth inhibition test was performed in a manner similar to that described by Black (2). The indirect immunofluorescence test has been described (5).

Ureaplasma strains. Initial studies were made with antisera to the eight "representative" bovine strains derived from the cloned strains previously described (6) by filtering broth cultures (450-nm membrane filter, Millipore Corp.) and picking single colonies one more time. Seventy-seven fresh isolates were studied. Twenty-five of these were from the respiratory tract of calves in Denmark provided by $\mathbf{N}$. Friis. Twelve were isolated from the urogenital tract of cattle in Canada, provided by R. B. Truscott. Two strains were isolated from the pneumonic lungs of calves in the United States by E. E. Ose. The remaining strains were isolated in the United Kingdom from the respiratory tract or the urogenital tract of cattle. 
The human ureaplasma strains of serotypes I to VIII (12) were obtained from F. T. Black.

Cloning of strains was by filtering broth cultures through a 450-nm membrane filter (Millipore Corp.) and picking single colonies on three successive occasions as previously described (5).

\section{RESULTS}

Since the ureaplasma clones used in this study were derived from those previously described (6) by picking single colonies a further time and also since the growth medium had been modified, cross-reactions between the eight previously proposed representative strains (listed in Table 1) were reexamined by the immunofluorescence and growth inhibition tests. The results are given in Table 1 for the indirect immunofluorescence test (see Table 5 for the growth inhibition test results). The eight strains were also examined by immunofluorescence when grown on the U3 medium used previously (6). On this medium the results obtained were almost identical to those previously reported.

Initially all the new isolates were examined to determine whether they reacted in the growth inhibition test with antisera raised against the eight representative strains listed in Table 1 . Zones of inhibition of greater than $2 \mathrm{~mm}$ from the edge of the well containing the antiserum were considered positive. Cultures that reacted with a single antiserum were not examined further. All cultures that reacted with more than one of the antisera were cloned and retested since it was possible that such results might be due to cultures being mixed. The cultures that did not show any inhibition of growth with any of the eight antisera were also cloned and retested since mixtures of serotypes might mask any inhibition of one of the serotypes in a mixture.

The results of these studies are shown in Table 2. Of the 77 strains isolated from cattle in the United Kingdom, Denmark, the United States, and Canada, only 5 did not show a reaction with any of the eight antisera (strains T45, F27, T74, T75, T71). Fifty-two strains reacted with only 1 antiserum of the 8 , whereas 20 strains showed inhibition of growth with two or more of the antisera. The reactions of these 20 strains with the antisera to the 8 representative strains are shown in Table 3.

We then investigated further whether the five strains (T45, F27, T74, T75, T71) which had not reacted with antisera to the eight representative strains shared any antigens with other bovine ureaplasmas. Antisera were raised in rabbits against these five cloned strains. Antisera were also raised against six of the strains which crossreacted with more than one of the original eight representative antisera, since it was possible that these strains might induce an antibody response against a larger number of antigens. These 11 antisera were then tested by the growth inhibition test against the 11 strains and also the original 8 representative strains (Table 4).

Two of the five "nonreactor" strains appeared similar to each other (T45, F27) and shared antigens with strains A417, Mmb167, Bu2, T73, $\mathrm{T} 510$, and T53. Nonreactor strains T74 and T75

TABLE 1. Serological relation between eight bovine ureaplasmas determined by immunofluorescence

\begin{tabular}{lcccccccc}
\hline & \multicolumn{7}{c}{ Titer with strain used as antigen } \\
\cline { 2 - 9 } Antiserum against: & A417 & T95 & T288 & Mmb167 & Bu2 & D48 & T315 & T44 \\
\hline A417 & 640 & $\overline{-}^{a}$ & - & - & 320 & - & - & - \\
T95 & 160 & 1,280 & - & - & 80 & - & - & - \\
T288 & 640 & - & 1,280 & - & 320 & - & - & - \\
Mmb167 & - & - & - & 1,280 & 320 & - & - & - \\
Bu2 & 80 & - & - & 80 & 1,280 & - & - & - \\
D48 & - & - & - & - & - & 640 & - & - \\
T315 & - & - & - & - & - & 640 & 1,280 & - \\
T44 & - & - & - & - & - & - & - & 1,280 \\
\hline
\end{tabular}

${ }^{a}$ Dashes indicate a titer of $<20$.

TABLE 2. Reaction in the growth inhibition test of 77 bovine ureaplasma strains

\begin{tabular}{lccccccccccc}
\hline & \multicolumn{1}{c}{ No. of strains inhibited ${ }^{a}$ with antisera to strain: } \\
\cline { 2 - 11 } Source of isolate & A417 & T95 & T288 & Mmb167 & Bu2 & D48 & T315 & T44 & $\begin{array}{c}\text { None } \\
\begin{array}{c}\text { More than } \\
\text { one }\end{array}\end{array}$ Total \\
\hline $\begin{array}{l}\text { Respiratory } \\
\begin{array}{l}\text { tract } \\
\text { Urogenital tract }\end{array}\end{array}$ & 7 & 4 & 1 & 1 & 3 & 15 & & 3 & 7 & 41 \\
\hline
\end{tabular}

\footnotetext{
${ }^{a}$ Zone of $>2 \mathrm{~mm}$ regarded as positive.
} 
TABLE 3. Size of zone of inhibition of growth of bovine ureaplasma strains reacting with more than one antiserum

\begin{tabular}{|c|c|c|c|c|c|c|c|c|}
\hline \multirow{2}{*}{ Strain used as antigen } & \multicolumn{8}{|c|}{ Sixe of zone of growth inhibition (mm) } \\
\hline & $\mathrm{A} 417^{a}$ & T95 & $\mathrm{T} 288$ & Mmb167 & Bu2 & D48 & T315 & $\mathrm{T} 44$ \\
\hline VSN3T & 5 & 5 & 5 & 5 & 4 & & 4 & 5 \\
\hline T56 & 7 & 4 & 5 & 4 & 4 & & & \\
\hline $\mathrm{T} 510$ & 4 & & 5 & 4 & 3 & & 4 & \\
\hline $\mathrm{D} 227$ & 7 & 4 & 5 & 6 & 6 & & & \\
\hline T73 & 7 & 4 & 4 & 2 & 5 & & & \\
\hline T53 & 6 & 5 & 5 & 6 & 8 & & & \\
\hline T55 & 5 & & 5 & 3 & 4 & & & \\
\hline $1510 / 11 \mathrm{~T}$ & 4 & & 2 & 2 & 3 & & & \\
\hline T54 & 5 & & 3 & 3 & 2 & & & \\
\hline F10 & 4 & & 3 & 3 & 3 & & & \\
\hline F13 & 3 & & 3 & 3 & & & & \\
\hline F21 & 5 & & & 3 & 2 & & 5 & \\
\hline T622 & 4 & & & 6 & & 5 & 7 & \\
\hline F7 & & & & 3 & & 7 & 4 & \\
\hline F16 & 5 & & & & & & 7 & \\
\hline T312 & 3 & & & & & & 6 & \\
\hline T619 & 3 & & & & & & 2 & \\
\hline C1427 & 3 & & & & 6 & & & \\
\hline T615 & 4 & & & & 4 & & & \\
\hline T319 & & & & & & 5 & 2 & \\
\hline
\end{tabular}

${ }^{a}$ Antiserum to strain.

TABLE 4. Serological relation between 19 bovine ureaplasma strains examined by growth inhibition ${ }^{a}$

\begin{tabular}{|c|c|c|c|c|c|c|c|c|c|c|c|}
\hline \multirow{2}{*}{ Strain } & \multicolumn{11}{|c|}{ Size of zone of growth inhibition (mm) } \\
\hline & $\mathrm{T} 45^{a}$ & F27 & $\mathrm{T} 74$ & $\mathrm{~T} 75$ & T71 & $\mathrm{T} 73$ & T510 & T53 & F10 & F16 & T622 \\
\hline $\mathrm{T} 45$ & 7 & & & & & 6 & & 5 & 2 & & \\
\hline F27 & 2 & 8 & & & & 3 & 2 & & & & \\
\hline T74 & & & 7 & 4 & & & & & & & \\
\hline $\mathrm{T} 75$ & & & 6 & 2 & & & & & & & \\
\hline $\mathrm{T} 71$ & & & & & 7 & & & & & & \\
\hline T73 & 5 & 5 & & & & 6 & 6 & 6 & 5 & 2 & \\
\hline T510 & 5 & 6 & & 2 & & 3 & 5 & 5 & 4 & & \\
\hline $\mathrm{T} 53$ & 3 & 6 & & & & 5 & 4 & 7 & 5 & & \\
\hline F10 & & & & & & 3 & & 3 & 6 & & \\
\hline F16 & & & & & 4 & 2 & & & & 5 & 4 \\
\hline T622 & & & & & & 4 & & & & & 5 \\
\hline A417 & 3 & 4 & & & & 5 & 3 & 5 & 3 & & \\
\hline T95 & & & & & & 2 & & 2 & & & \\
\hline $\mathrm{T} 288$ & & & & & & 3 & 2 & 2 & & & \\
\hline Mmb167 & 4 & 5 & & & & 5 & 5 & 6 & 5 & & \\
\hline $\mathrm{Bu} 2$ & 2 & 2 & & & & 4 & 2 & 6 & 2 & & \\
\hline D48 & & & & & & & & & & & 9 \\
\hline T315 & & & & & & & & & & & \\
\hline $\mathrm{T} 44$ & & & & & & & & & & & \\
\hline
\end{tabular}

${ }^{a}$ Antiserum to strain.

shared antigens, and antiserum to strain T75 inhibited the growth of strain T510. Strain T71 possessed antigens in common with strain F16. Antisera raised against the "multiple reactor" strains T73, T510, T53, and F10 inhibited the growth of strains T45 or F27, confirming a relationship between these latter two strains and other bovine ureaplasmas. The reactions of the antisera to strains $\mathrm{T} 73, \mathrm{~T} 510, \mathrm{~T} 53$, and $\mathrm{F} 10$ confirmed a relationship, indicated in Table 3, between these four strains and certain of the original eight representative strains, namely A417, T95, T288, Mmb167, and Bu2. Strains F16 and T622 were found to share antigens with each other and with strain D48, one of the original eight strains. 
TABLE 5. Serological relation between 11 proposed representative bovine ureaplasmas tested by growth inhibition

\begin{tabular}{lccccccccccc}
\hline \multirow{2}{*}{ Strain } & \multicolumn{10}{c}{ Size of zone of growth inhibition (mm) } \\
\cline { 2 - 12 } & A417 & Bu2 & Mmb167 & T95 & T288 & T45 & D48 & T315 & T44 & T74 & T71 \\
\hline A417 & 5 & 4 & 2 & 2 & 2 & 3 & & & & & \\
Bu2 & 2 & 6 & 3 & & & 2 & & & & \\
Mmb167 & 2 & 4 & 7 & & 2 & 4 & & & & \\
T95 & 2 & 3 & & 5 & & & & & & \\
T288 & 2 & 2 & 2 & 2 & 6 & 7 & & & & \\
T45 & & & & & & 7 & 6 & 7 & & \\
D48 & & & & & & & & 7 & 4 & & \\
T315 & & & & & & & & & & 7 & \\
T44 & & & & & & & & & & & 7 \\
T74 & &
\end{tabular}

${ }^{a}$ Antiserum to strain.

Thus, to select strains representative of the diversity of antigenic structure observed among bovine ureaplasmas, it was considered that strains T45, T74, and T71 should be added to the original eight. The relationship between these 11 strains by the growth inhibition test is shown in Table 5.

More cross-reactions were observed among the bovine ureaplasmas in these studies than in the original study using immunofluorescence (6). Also, three more strains had been added to the list of representative bovine strains. Thus, it was important to determine whether there was any antigenic relationship between these 11 representative bovine ureaplasmas and the eight serotypes of $U$. urealyticum. Antisera to the eight human serotypes was tested against the 11 representative bovine strains and also the other bovine strains listed in Table 4. Antisera to all 19 bovine strains in Table 4 were also tested against the eight human serotypes grown on $\mathrm{U} 4$ medium. No cross-reactions between the bovine and human strains were detected in the growth inhibition test.

\section{DISCUSSION}

The bovine ureaplasmas are serologically extremely heterogeneous. No neat circumscribed serotypes exist although clusters of strains with a certain amount of antigenic similarity have been described (6). However, strains exist which synthesize antigens common to strains in more than one cluster. Thus, the antigenic nature of the bovine ureaplasmas is perhaps even less ordered than previously indicated. A change in the antigenic structure of $U$. urealyticum when grown in different media has also been reported (10). The results obtained in these studies also indicate such a change.

At first sight these findings with the bovine ureaplasmas seem to indicate a basic difference in antigenic structure between them and $U$. urealyticum, the human ureaplasmas, within which eight serotypes have been recognized (12). However, it should be noted that other studies with the ureaplasmas of human origin demonstrated a more complex situation more akin to the situation with the bovine strains (8). Only careful selection and study of strains by Ford (4) and Black (1) has led to the apparently simple system now proposed (12). However, as crossreactions between certain of the eight serotypes of $U$. urealyticum have been reported $(2,11)$, it is possible that completely distinct serotypes of $U$. urealyticum do not exist.

Our current view on the antigenic structure of bovine ureaplasmas is that a variety of antigenic determinants exist, which are detectable by the growth inhibition test, and a particular ureaplasma isolate may express various combinations of these determinants. It is thus difficult to propose distinct serotypes for the bovine ureaplasmas. However, by selecting a number of strains, such as the 11 listed in Table 5, the antigenic diversity of the group can be represented. Isolates from disease conditions can then be tested with the representative antisera and it should be possible to determine the association with disease of organisms synthesizing particular antigens.

No common antigens were demonstrated, by the growth inhibition test on the same solid medium, between the 19 bovine ureaplasma strains listed in Table 4 and the eight serotypes of $U$. urealyticum. Of these 19 strains, 11 were the representative bovine strains selected out of more than 100 strains examined in this study and earlier (6). Thus, although serologically heterogeneous, the bovine ureaplasmas seem to comprise a group of organisms with many common antigens but which, as a group, are distinct from the human strains comprising the species 
$U$. urealyticum. This finding, together with the earlier demonstration that the guanine and cytosine contents of $U$. urealyticum and the bovine ureaplasmas differ to an extent that denotes the existence of two distinguishable populations $(3,7)$, indicates that the bovine ureaplasmas should be regarded as a group distinct from $U$. urealyticum. Perhaps a second species or subspecies of Ureaplasma should be proposed represented by the 11 strains in Table 5 .

\section{LTERATURE CITED}

1. Black, F. T. 1970 . Serological methods for classification of human T-mycoplasmas, 407-411. In Fifth International Congress of Infectious Diseases, Vienna, vol. 1. Wiener Medizinischen Akademie.

2. Black, F. T. 1973. Modifications of the growth inhibition test and its application to human T-mycoplasmas. Appl. Microbiol. 25:528-533.

3. Black, F. T., C. Christiansen, and G. Askaa. 1972 Genome size and base composition of deoxyribonucleic acid from eight human T-mycoplasmas. Int. J. Syst. Bacteriol. 22:241-242.

4. Ford, D. K. 1967. Relationships between mycoplasma and the etiology of nongonococcal urethritis and Reiters syndrome. Ann. N. Y. Acad. Sci. 143:501-504.

5. Howard, C. J., and R. N. Gourlay. 1973. Serological comparison of bovine T-mycoplasmas. J. Gen. Microbiol. 79:127-134.
6. Howard, C. J., R. N. Gourlay, and J. Collins. 1975. Serological comparison between twenty-five bovine ureaplasma ( $T$-mycoplasma) strains by immunofluorescence. Int. J. Syst. Bacteriol. 25:155-159.

7. Howard, C. J., R. N. Gourlay, D. J. Garwes, D. H. Pocock, and J. Collins. 1974. Base composition of deoxyribonucleic acid from bovine T-mycoplasmas. Int. J. Syst. Bacteriol. 24:373-374.

8. Lin, J.-S. L., M. I. Kendrick, and E. H. Kass. 1972. Serologic typing of human genital T-mycoplasmas by a complement-dependent mycoplasmacidal test. J. Infect. Dis. 126:658-663.

9. Livingston, C. W., and B. B. Gauer. 1974. Serologic typing of T-strain mycoplasma isolated from the respiratory and reproductive tracts of cattle in the United States. Am. J. Vet. Res. 35:1469-1471.

10. Masover, G. K., R. P. Mischak, and L. Hayflick. 1975. Some effects of growth medium composition on the antigenicity of a T-strain mycoplasma. Infect. Immun. 11:530-539.

11. Piot, P. 1977. Comparison of growth inhibition and immunofluorescence tests in serotyping clinical isolates of Ureaplasma urealyticum. Br. J. Vener. Dis. 53: 186-189.

12. Shepard, M. C., C. D. Lunceford, D. K. Ford, R. H. Purcell, D. Taylor-Robinson, S. Razin, and F. T. Black. 1974. Ureaplasma urealyticum gen. nov., sp. nov.: proposed nomenclature for the human $\mathrm{T}$-(Tstrain) mycoplasma. Int. J. Syst. Bacteriol. 24:160-171.

13. Taylor-Robinson, D., and P. M. Furr. 1973. The distribution of T-mycoplasmas within and among various animal species. Ann. N.Y. Acad. Sci. 225:108-117. 